\title{
Release of MICAL Autoinhibition by Semaphorin-Plexin Signaling Promotes Interaction with Collapsin Response Mediator Protein
}

\author{
Eric F. Schmidt, Sang-Ohk Shim, and Stephen M. Strittmatter \\ Program in Cellular Neuroscience, Neurodegeneration, and Repair, Yale University School of Medicine, New Haven, Connecticut 06536
}

\begin{abstract}
Semaphorin activation of Plexin (Plex) receptors provides axonal guidance during neuronal development. Two families of cytoplasmic proteins, collapsin response mediator proteins (CRMPs) and molecules interacting with CasL (MICALs), have been implicated in Plexin function. The relationship between CRMP and MICAL signaling has not been defined nor is the mechanism by which Plexin activates MICAL clear. Here, we show that CRMP and MICAL physically associate and that Sema signaling promotes this association. MICAL enzymatic activity is inhibited by the C-terminal domain of MICAL. CRMP and Plexin associate with nonenzymatic and enzymatic domains of MICAL and together release MICAL enzymatic autoinhibition. In addition to acting as an upstream MICAL activator, CRMP functions downstream of MICAL, inhibiting the catalytic domain. A constitutively active CRMP mutant inhibits MICAL activity more potently than does wild-type CRMP, suggesting that CRMP or a CRMP-associated factor is a MICAL substrate. Thus, complex Plex/CRMP/ MICAL interactions transduce Semaphorin signaling into axon guidance.
\end{abstract}

Key words: plexin; neuropilin; semaphorin; MICAL; axonal guidance; growth cone collapse; CRMP

\section{Introduction}

Accurate axonal guidance during development is essential for neuronal function. Semaphorins are an important class of extracellular guidance cues, and Sema3A is the prototypical axonal repellant. Recent work has made it clear that Sema3A signaling involves several intracellular pathways mediating a variety of cellular responses (for review, see Pasterkamp and Kolodkin, 2003). After the binding of Sema3A to the coreceptor complex consisting of members of the Plexin-A (PlexA) and neuropilin-1 (NRP1) families of proteins (He and Tessier-Lavigne, 1997; Kolodkin et al., 1997; Takahashi et al., 1999; Tamagnone et al., 1999), neuronal growth cones collapse as a result of the dramatic rearrangement of the actin cytoskeleton and endocytosis of the plasma membrane (Luo et al., 1993; Fournier et al., 2000; Jurney et al., 2002; Castellani et al., 2004). A role for Rho-like GTPases (Jin and Strittmatter, 1997; Zanata et al., 2002; Turner et al., 2004; Toyofuku et al., 2005), protein phosphorylation (Aizawa et al., 2001; Eickholt et al., 2002; Mitsui et al., 2002; Sasaki et al., 2002), RanBPM (Togashi et al., 2006), and members of the collapsin response mediator protein (CRMP) family (Goshima et al., 1995; Deo et al., 2004) have all been shown to play a role in Sema3A signal transduction. In addition, the intracellular molecule interacting with CasL (MICAL) has been shown to bind to PlexA

\footnotetext{
Received Sept. 12, 2006; revised Jan. 16, 2008; accepted Jan. 17, 2008.

This work was supported by a research grant from the National Institutes of Health (NIH) (S.M.S.) and by an NIH Individual Predoctoral Training Grant (E.F.S.).

Correspondence should be addressed to Stephen M. Strittmatter, Program in Cellular Neuroscience, Neurodegeneration, and Repair, Yale University School of Medicine, P.0. Box 9812, New Haven, CT 06536-0812. E-mail: stephen.strittmatter@yale.edu.

DOI:10.1523/JNEUROSCI.5646-07.2008

Copyright $\odot 2008$ Society for Neuroscience $\quad$ 0270-6474/08/282287-11\$15.00/0
}

receptors in Drosophila and is required for proper guidance of motor axons (Terman et al., 2002).

MICAL was first identified in a protein interaction screen looking for novel binding partners for the signaling protein CasL (Suzuki et al., 2002). MICAL contains a number of conserved protein interaction domains, including a calponin homology $(\mathrm{CH})$ domain, LIM (the three gene products Lin-11, Isl-1, and Mec-3) domain, multiple coiled-coil ERM (ezrin/radixin/moesin domain) $\alpha$-like motifs, proline-rich regions, and glutamic acid rich repeats (Suzuki et al., 2002; Terman et al., 2002; Weide et al., 2003). At least three MICAL genes, MICAL1-3, have been identified in vertebrates (Suzuki et al., 2002; Terman et al., 2002; Pasterkamp et al., 2005). MICAL may provide a link to cytoskeletal dynamics and vesicle trafficking. $\mathrm{CH}$ domains in other proteins bind and/or regulate actin (Gimona et al., 2002). The SH3 domain of CasL is involved in $\beta 1$-integrin signaling (Sattler et al., 1997 ) and binds to the PPKPP sequence of MICAL1 (Suzuki et al., 2002). MICAL also associates with microtubules (Fischer et al., 2005) and vimentin (Suzuki et al., 2002). The interaction of MICAL1 and 3 with Rab1 may contribute to organelle trafficking (Weide et al., 2003; Fischer et al., 2005).

All members of the MICAL gene family have a highly conserved $\sim 500$ amino acid stretch at their $\mathrm{N}$ terminus, which contains three characteristic flavin adenine dinucleotide (FAD)binding motifs present on flavin monooxygenases participating in oxidation-reduction (redox) reactions (Terman et al., 2002). The crystal structure of the monooxygenase (MO) domain of mouse MICAL1 reveals that it shares a structural homology to aromatic hydroxylases, such as p-hydroxybenzoate hydroxylase (pHBH) from Pseudomonas fluorescens (Nadella et al., 2005; Siebold et al., 2005), and has detectable enzymatic activity 
(Nadella et al., 2005). MICAL is an NADPH-dependent enzyme, consistent with monooxygenase function (Massey, 1995). Although to date, no substrates have been identified, structural analyses suggest that the substrate for MICAL is likely an amino acid side chain of a positively charged macromolecule, such as a protein (Siebold et al., 2005).

A yeast two-hybrid screen using the $\mathrm{C} 2$ intracellular domain of Drosophila PlexA, a region highly conserved between PlexA family members, identified MICAL as a novel Plexin-interacting protein (Terman et al., 2002). Flies null for the MICAL gene exhibited dramatic axon pathfinding deficits in Sema1Asensitive motor axons and had a strong genetic interaction with Sema1A and PlexA mutant flies (Terman et al., 2002). Most interesting was the observation that proper axon guidance was dependent on MICAL enzymatic activity, because flies with point mutations in the FAD-binding domain displayed the same phenotype as those lacking the MICAL gene altogether (Terman et al., 2002). Pharmacological studies have shown the green tea extract, (-)epigallocatechin gallate (EGCG), a specific inhibitor of flavin monooxygenases, is able to block Sema3A- and Sema3Fmediated axonal repulsion in mammalian systems (Terman et al., 2002; Pasterkamp et al., 2005). This effect is specific to class 3 semaphorins, because EGCG treatment did not alter responses to Sema6A, slit, ephrinAs, or myelin (Pasterkamp et al., 2005).

The goal of the current study was to explore the relationship of MICAL to other known PlexA-interacting proteins, namely CRMPs (Deo et al., 2004). In addition, we examine the effect of full-length MICAL and truncation mutants of MICAL on COS-7 cell morphology and develop an assay to measure the monooxygenase activity of MICAL mutants in transfected human embryonic kidney 293T (HEK293T) cell lysates. The data presented here demonstrate that MICAL is a CRMP-interacting protein, and the FAD-binding domain is constitutively active (CA) in COS-7 cells and neurons. Additionally, the enzymatic activity appears to be autoregulated by the C-terminal domain of MICAL, and overexpression of the C-terminal domain acts in a dominant-negative manner to attenuate Sema3A signaling. Finally, overexpression of the C-terminal domain is sufficient to block neuronal responses to Sema3 A in neurons.

\section{Materials and Methods}

Expression plasmids, viral vectors, and recombinant proteins. The expression plasmids for Myc-PlexA1, Myc-PlexA3, Myc-PlexA1 $\Delta$ ect, MycPlexA1cyto, bicistronic Myc-PlexA1/HA-NRP1, alkaline phosphatase (AP)-Sema3A, AP-Sema3F, V5-CRMP1-4, and V5-mCRMP1(49-56) have been described previously (Takahashi et al., 1999; Takahashi and Strittmatter, 2001; Deo et al., 2004). Full-length Myc-MICAL1-pRK5 was a generous gift from Dr. A. Kolodkin (Johns Hopkins University, Baltimore, MD). Mouse MICAL1 truncation mutants or LIM domain were constructed by amplifying the coding regions for amino acids $1-450,1-630,1-760,451-1048,631-1048,761-1048$, or $631-760$ by $\mathrm{PCR}$ and subcloning the products into pcDNA3.1-Myc/His (Invitrogen, San Diego, CA) between BamHI and XhoI. V5-MICAL1 was constructed using the pcDNA3.1-V5/His-TOPO cloning kit (Invitrogen) using PCRamplified coding regions for amino acids 1-1048. For GST fusion proteins, coding regions for amino acids $8-525$ of wild-type (WT) CRMP1 or mCRMP1 (49-56), or 761-1048 of mouse MICAL1 were amplified by PCR and subcloned into pGEX-6P-1 between BamHI and XhoI.

Chemically competent BL21-Gold(DE3) Escherichia coli (Clontech, Mountain View, CA) were transformed with GST fusion protein expression plasmids or empty pGEX-6P-1 vector. Expression was induced by the addition of $1 \mathrm{~mm}$ isopropyl- $\beta$-D-thiogalactoside, and cells were grown for $12-15 \mathrm{~h}$ at room temperature. Cells were lysed by sonication in buffer containing $50 \mathrm{~mm}$ HEPES, pH 7.5, $150 \mathrm{~mm} \mathrm{KCl,} 1 \mathrm{~mm}$ DTT, and $1 \times$ EDTA-free protease inhibitor mixture (Roche Diagnostics, India- napolis, IN). Lysates were cleared by centrifugation and filtration through a $0.22 \mu \mathrm{m}$ filter, and GST fusion protein was batch purified by affinity chromatography using glutathione- $S$ transferase-conjugated resin (GE Healthcare, Arlington Heights, IL). Bound protein was eluted with $15 \mathrm{~mm}$ reduced glutathione, $50 \mathrm{~mm}$ Tris, $\mathrm{pH}$ 8.5, and elutions were dialyzed against $20 \mathrm{~mm}$ HEPES, $\mathrm{pH} 7.5$, and $100 \mathrm{~mm} \mathrm{NaCl}$.

To make AP-conditioned media, HEK293T cells were transiently transfected with expression plasmids for AP-Sema3A, AP-Sema3F, or pcAP6 vector and grown in DMEM (Invitrogen) with 10\% fetal bovine serum (FBS) (Invitrogen) and 1\% penicillin/streptomycin (Invitrogen). After $5 \mathrm{~d}$, conditioned media was collected, filtered with a $0.22 \mu \mathrm{m}$ filter, and stored at $-80^{\circ}$. Concentration of AP protein was determined using the pNPP assay (Pierce, Rockford, IL).

For viral vectors, the coding region of full-length and truncation mutants of MICAL1, including the Myc/His epitope tag, were amplified by PCR from the respective pcDNA3.1-Myc/His expression vectors and then ligated into pHSVPrPUC between the BamHI and EcoRI sites. The production of recombinant Herpes Simplex Virus (HSV) has been described previously (Takahashi et al., 1999). Conditioned media containing the virus was used for experiments.

Immunoprecipitations and cell morphology assays. HEK293T cells were cultured in DMEM with $10 \%$ FBS and $1 \%$ penicillin/streptomycin and grown on six-well tissue culture plates. Cells were transfected with $2 \mu \mathrm{g}$ of DNA with $6 \mu$ l of Fugene- 6 transfection reagent (Roche Diagnostics) in $100 \mu \mathrm{l}$ of serum-free DMEM and allowed to grow for $36-48 \mathrm{~h}$. Cells were lysed on ice in $500 \mu \mathrm{l}$ buffer containing $20 \mathrm{~mm}$ Tris, pH 7.5, $150 \mathrm{NaCl}, 1$ mM EDTA, $1 \%$ Triton X-100, 1 mM PMSF, and $1 \times$ protease inhibitor mixture (Roche Diagnostics), and lysates were cleared by centrifugation. Fifty microliters of supernatant was saved for analysis (input). Lysates were incubated with monoclonal anti-Myc or anti-V5 antibodyconjugated agarose beads (Sigma, St. Louis, MO) for $1-3 \mathrm{~h}$ at $4^{\circ}$. Beads were washed four times with $750 \mu \mathrm{l}$ wash buffer containing $0.1 \%$ Triton $\mathrm{X}-100,20 \mathrm{~mm}$ Tris, $\mathrm{pH}$ 7.5, $150 \mathrm{~mm} \mathrm{NaCl}, 1 \mathrm{~mm}$ EDTA, and bound protein was eluted by the addition of $2 \times$ Laemli's sample buffer. Eluates were analyzed by SDS-PAGE and Western blotting using anti-Myc (9E10; Santa Cruz Biotechnology, Santa Cruz, CA) or anti-V5 (Invitrogen) primary antibodies, AP-conjugated anti-mouse secondary antibodies, and visualized with the nitroblue-tetrazolium-chloride (NBT)/5bromo-4-chlor-indolyl-phosphate (BCIP) alkaline phosphatase substrates.

For Sema3A treatment, HEK293T cells were cotransfected with MycPlexA1/HA-NRP1 bicistronic plasmid, V5-CRMP1, and V5-MICAL1 and grown for $36 \mathrm{~h}$. Cells were then equilibrated to room temperature for 30 min with the addition of $50 \mathrm{~mm}$ HEPES, pH 7.5, to the media. APSema3A or AP-conditioned media was added to each well at a final concentration of $\sim 1 \mathrm{nM}$, and cells were incubated for an additional 30 min. Immunoprecipitations were performed as described above, except $0.1 \mathrm{~nm}$ AP-Sema3A or AP conditioned media was included in the lysis buffer.

To test the effect of MICAL truncation mutants on cell morphology, COS-7 cells were transfected with expression plasmids using the Fugene-6 transfection method (Roche Diagnostics) and grown in sixwell plates. After $12 \mathrm{~h}$, cells were replated into 24-well plates at a low density and grown for an additional $24 \mathrm{~h}$ before being fixed with $3.7 \%$ formaldehyde in PBS. Transfected cells were visualized by immunofluorescent staining with anti-Myc primary antibodies (9E10; Sigma) and Alexa Flour-488-conjugated anti-mouse secondary antibodies (Invitrogen, Eugene, OR). Immunofluorescence images were captured using a CCD camera attached to an Olympus Optical (Center Valley, PA), microscope, and cell area was measured using Scion (Frederick, MD) Image Analysis software. In testing Sema3A-mediated contraction, cells were transfected and replated as above. Cells were then incubated with APSema3A or AP-Sema3F conditioned media at a final AP concentration of $\sim 1 \mathrm{nM}$ for 60 min before being rapidly washed three times with ice-cold HBH (HEPES buffered HBSS) with $0.1 \%$ BSA and fixed with $3.7 \%$ formaldehyde in $20 \mathrm{~mm}$ HEPES, pH 7.5, and $150 \mathrm{~mm} \mathrm{NaCl}$. Cells were visualized by staining for bound AP using the BCIP/NBT alkaline phosphatase substrates. Transmitted light images were captured, and cell area was measured as described above. 
A

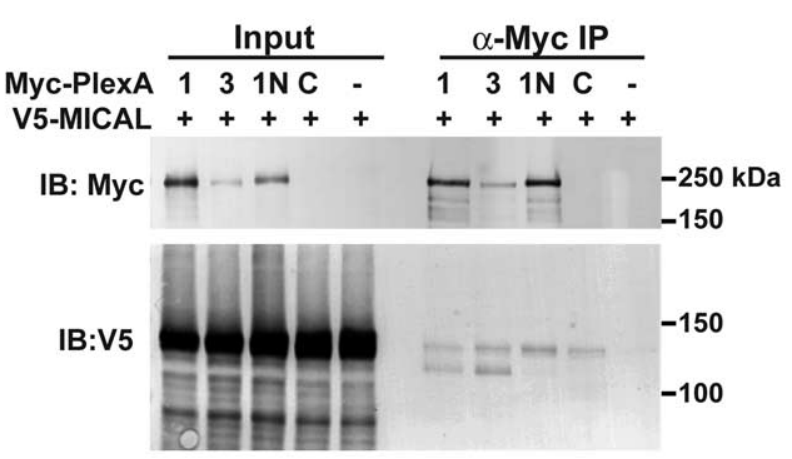

B

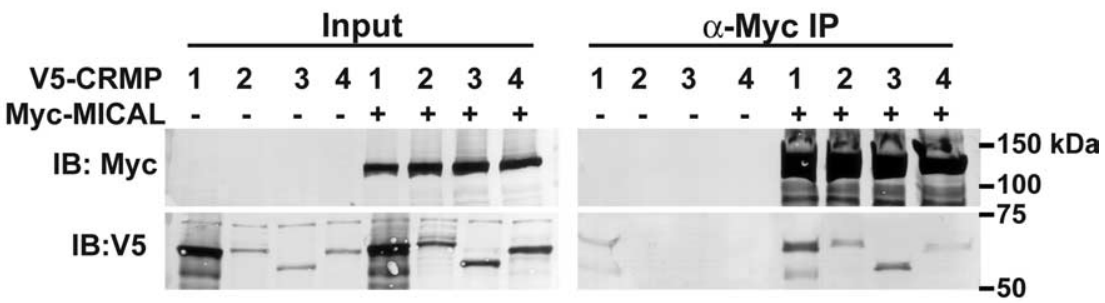

C

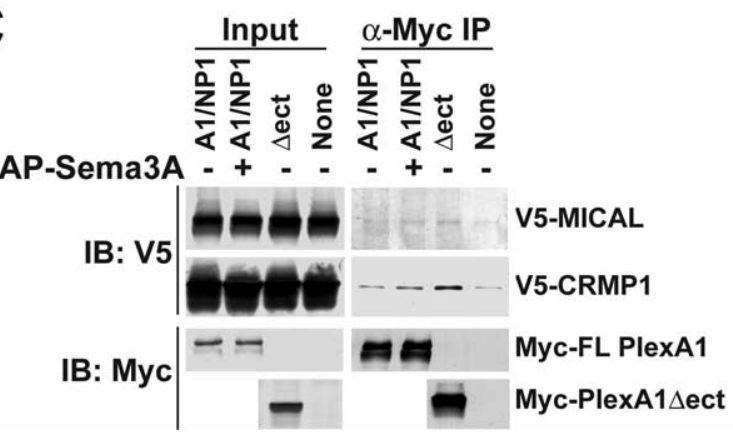

Figure 1. MICAL forms a Sema3A-modulated complex with CRMP and PlexA proteins. A, HEK293T cells were transfected with plasmids encoding the indicated proteins (1, PlexA1; 3, PlexA3; 1N, PlexA1/NRP1; C, PlexA1cyto). Lysates were then immunoprecipitated (IP) with anti-Myc antibodies, and Western blots were probed for Myc or V5 immunoreactivity. V5-MICAL were coimmunoprecipitated with both full-length PlexA1 and PlexA1cyto. The presence of NRP1 had no effect on the Plex-MICAL interaction. The expression of PlexA1cyto is equal to that of full-length PlexA1 (data not shown) but is not visible in the molecular weight range probed for full-length PlexA1. B, V5-CRMP1, 2, 3, and 4 all were able to coimmunoprecipitate with Myc-MICAL1 from transfected HEK293T cell lysates. C, Immunoprecipitations of HEK293T lysates expressing V5-MICAL, V5-CRMP1, and MycPlexA1/NRP1 (A1/NP1), Myc-PlexA1 $\Delta$ ect ( $\Delta$ ect), or vector (None). CRMP1 and MICAL were coimmunoprecipitated in a complex with Plexin proteins. Sema3A treatment or constitutively active PlexA1 1 ect increased the amount of CRMP1 and MICAL that coimmunoprecipitated. Each result is representative of three to five separate experiments with similar results.

HSV infection and neurite outgrowth. The culture and HSV infection of chick dorsal root ganglion (DRGs) neurons has been described previously (Takahashi et al., 1999). Briefly, DRGs were dissected from embryonic day 7 (E7) chick embryos and dissociated with trypsin-EDTA (Invitrogen). Cell suspensions were then incubated in F-12 media (Invitrogen) with 10\% FBS (Invitrogen), 1\% penicillin/streptomycin (Invitrogen), and $100 \mathrm{ng} / \mathrm{ml} \mathrm{NGF} \mathrm{(Sigma)} \mathrm{on} \mathrm{un-}$ coated plastic tissue culture plates with a 1:10 dilution of HSV conditioned media for 12-15 h. Cells were then replated on poly-D-lysine- and laminin-coated 96-well tissue culture plates (Costar, Cambridge, MA) and grown for $2 \mathrm{~h}$. Sema3A or clustered ephrin-A5 conditioned media containing $5 \mathrm{~nm}$ ligand was added, and cells were grown for an additional $5 \mathrm{~h}$ before being fixed with ice-cold PBS containing 3.7\% formaldehyde and $20 \%$ sucrose. Neurites were then visualized by immunofluorescent staining using monoclonal anti-Myc (9E10) and polyclonal anti-neurofilament-200 primary antibodies (Sigma) and Alexa-488 anti-mouse and Alexa-568 anti-rabbit secondary antibodies (Invitrogen). Neurite outgrowth was analyzed using the Molecular Devices (Union City, CA) Image Express system. The measurement of axonal growth cone collapse has been described previously (Nakamura et al., 1998).

\section{Results \\ MICAL1 forms a complex with PlexA proteins and CRMP}

It has been established that MICAL directly interacts with the C-terminal region of PlexA in flies, and this interaction mediates Drosophila Sema1A signaling (Terman et al., 2002). We examined interactions between mammalian MICAL and PlexA proteins. HEK293T cells were transfected with expression vectors for mouse V5-MICAL1 and mouse Myc-PlexA1, Myc-PlexA3, Myc-PlexA1/HA-NRP1 bicistronic plasmid, Myc-cytoplasmic domain of PlexA1 (PlexA1cyto), or pcDNA3.1-Myc-His vector. Lysates were subjected to anti-Myc immunoprecipitations, and eluates were separated by SDS-PAGE and immunoblotted

MICAL activity assay. The Amplex Red Hydrogen Peroxide/Peroxidase Assay kit (Invitrogen) has been used to measure hydrogen peroxide production from the purified enzymatic domain of MICAL1 (Nadella et al., 2005). We further adapted the kit to study the activity of MICAL1 truncation mutants in HEK293T cell lysates. Cells were transfected with expression plasmids encoding MICAL truncation mutants and grown for $36-48 \mathrm{~h}$. Cells were lysed by sonication in buffer containing $20 \mathrm{~mm}$ HEPES, pH 7.4, $100 \mathrm{~mm} \mathrm{NaCl}$, and 1× EDTA-free protease inhibitor mixture (Roche Diagnostics), and lysates were cleared by centrifugation. Reactions were performed in $100 \mu \mathrm{l}$ consisting of $50 \mu \mathrm{l}$ of cell lysate, $200 \mu \mathrm{M}$ NADPH, $6 \mu \mathrm{M}$ Amplex Red Reagent (10-acetyl-3,7dihydroxyphenoxazine), and $100 \mu \mathrm{U}$ HRP in 20 mM HEPES, pH 7.4, and $100 \mathrm{~mm} \mathrm{NaCl}$. Absorbance at $560 \mathrm{~nm}$ was measured using a Benchmark 96-well plate spectrophotometer (Bio-Rad, Hercules, CA) every minute for $5 \mathrm{~min}$. When testing the effects of GST fusion proteins on MICAL activity, the purified protein (in $20 \mathrm{~mm}$ HEPES, $100 \mathrm{mM} \mathrm{NaCl}$ ) was added to the reaction mixture at indicated concentrations. To test the effect of GST proteins on NADPH kinetics, the assay was performed as above, except the final concentration of NADPH was varied from 0 to $800 \mu \mathrm{M}$. with anti-Myc or anti-V5 antibodies. MICAL-V5 copurified with all of the Plexins tested, showing that these proteins can interact in mammalian systems (Fig. 1A). We next tested whether MICAL associates with members of the CRMP family of proteins, which we have shown to interact with PlexAl and mediate signaling (Deo et al., 2004). Anti-Myc immunoprecipitates of lysates of transfected cells demonstrated that V5-tagged CRMP1, 2, 3, and 4 all could form a complex with Myc-MICAL1 (Fig. $1 B$ ).

To test the significance of these interactions in the context of Sema3A signaling through PlexA receptors, anti-Myc immunoprecipitations were performed on lysates of HEK293T cells expressing Myc-PlexA1, HA-NRP1, V5-CRMP1, and V5-MICAL1 and stimulated with control or Sema3A conditioned media for 30 min. Although there was some background binding of V5CRMP1 and to the anti-Myc beads, treatment with Sema3A increased the amount of V5-CRMP that specifically coimmunoprecipitated with Myc-PlexA1 (Fig. 1C), similar to previous 
observations (Deo et al., 2004). V5MICAL1 also showed some nonspecific binding to Myc-beads; however, the amount of MICAL found in the immunoprecipitates was increased by Sema3A treatment (Fig. 1C). Additionally, more V5-CRMP1 and V5-MICAL1 copurified with the constitutively active MycPlexA1 1 ect compared with untreated fulllength Myc-PlexA1/NRP1 (Fig. 1C). These data suggest that activation of the PlexA1 receptor, either by ligand binding or by release of autoinhibition, leads to the stabilization of a complex containing Plexin, CRMP, and MICAL proteins.

Yeast two-hybrid studies have shown that the C-terminal region of MICAL1 is responsible for interactions with Plexins (Terman et al., 2002). In an attempt to map the region of MICAL responsible for mediating interactions with CRMPs, a series of MICAL1 truncation mutants (tMICALs) was generated. These mutant proteins were designed to contain a combination of the conserved protein-protein interaction domains found on the region of MICAL1 C-terminal to the FAD-binding monooxygenase domain (Fig. 2A). Anti-V5 immunoprecipitations of HEK293T cell lysates overexpressing Myc-tagged tMICAL proteins with either V5-CRMP1 or vector were performed. Analysis of the immunoprecipitates revealed that all tMICALs failed to interact with CRMP1 as strongly as full-length protein (Fig. $2 B, C$ ). However, tMICAL 1-760, which contains the FADbinding, $\mathrm{CH}$, and LIM domains coprecipitated with CRMP1 much more strongly than any of the other mutants. The C-terminal region, consisting of the poly-proline rich region and the coiled-coil domains failed to interact with CRMP1 directly, indicating that Plexin and CRMP interacting domains are separable. A comparison of tMICAL 1-760 with tMICAL 1-630 suggests that the LIM domain contributes to CRMP interaction. Although these observations suggest the LIM domain may be a site of CRMP binding, no direct interaction between the LIM domain alone and CRMP1 was detectable (data not shown). A comparison of tMICAL 1-760 with tMICAL 451-1048 suggests that the FADbinding domain also participates in CRMP interaction. However, the FAD-binding domain alone, tMICAL 1-450, was expressed at lower levels, so its direct interaction cannot be compared directly. Because it is thought that mouse MICAL1 forms a globular protein (Nadella et al., 2005), multiple residues located throughout the region spanning the FAD and LIM domains may mediate CRMP binding rather than a specific linear chain of amino acids.

The MICAL1 FAD-binding region mediates changes in cell morphology and is inhibited by the $\mathrm{C}$ terminus

The heterologous assay measuring changes in COS-7 cell morphology has become a useful method of studying semaphorin signaling in a non-neuronal system (Takahashi et al., 1999; Deo et al., 2004; Turner and Hall, 2006). Therefore, the effect of the overexpression of tMICAL proteins on COS-7 cell morphology was examined. COS-7 cells were transfected with full-length Myc-MICAL or one of the six tMICAL constructs. The cell area of anti-Myc-immunoreactive cells was measured, and the percentage of cells with an area $<1600 \mu \mathrm{m}^{2}$ was determined. Approximately $39 \%$ of COS-7 cells overexpressing full-length MICAL1 were contracted (Fig. 3). Surprisingly, overexpression of the FAD-binding domain alone (tMICAL 1-450), with the $\mathrm{CH}$ domain (tMICAL 1-630), or with the $\mathrm{CH}$ and LIM domains (tMICAL 1-760) resulted in contraction of $80-95 \%$ of cells, similar to overexpression of constitutively active PlexA1 $\Delta$ ect (Fig. 3B). Therefore, truncation of the C-terminal 290-600 amino acids results in constitutive activity. The cell contraction was likely not attributable to a toxic effect of the mutant protein, because cells showed no evidence of apoptosis (data not shown) and exhibited a round morphology with a few "spindle-like" processes (Fig. $3 A$ ) similar to PlexA1 $\Delta$ ect overexpressing and PlexA1/NRP1 overexpressing cells treated with Sema3A (Takahashi and Strittmatter, 2001). Overexpression of the full-length MICAL (FL-MICAL) protein yielded cell contraction percent- 
A
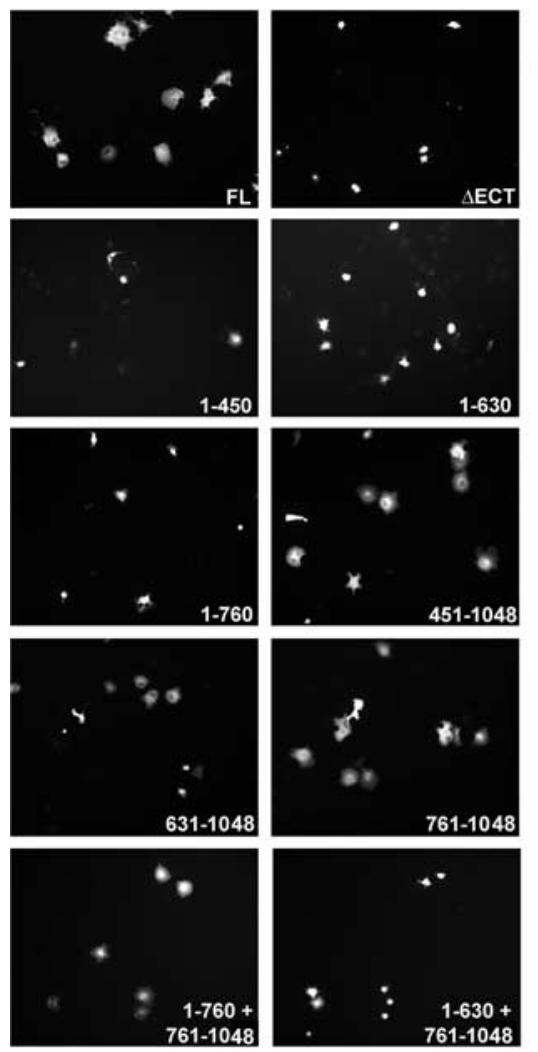

B
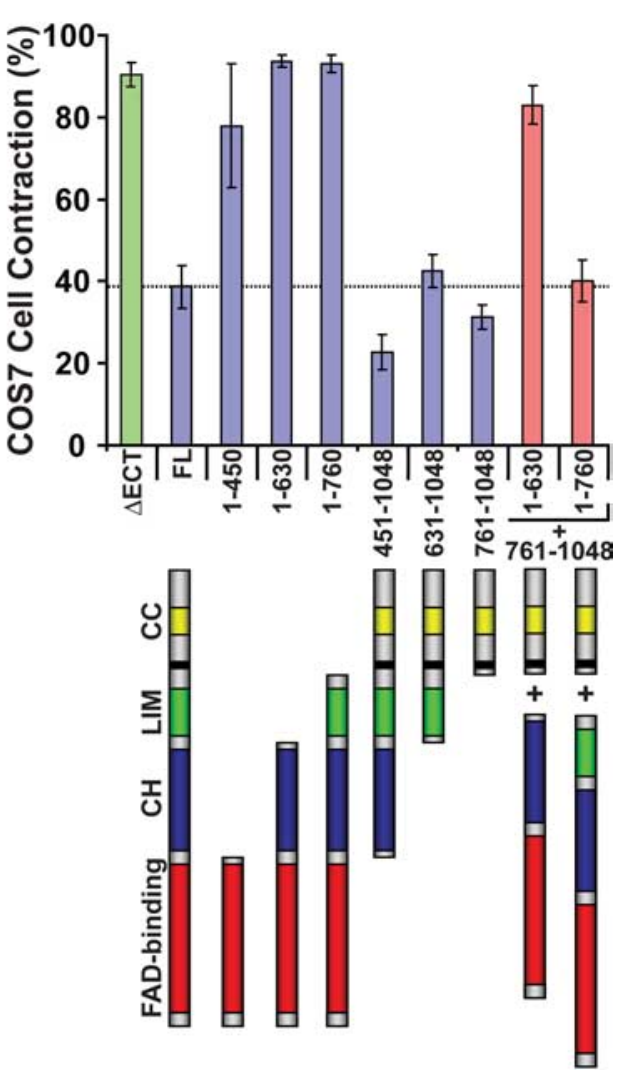

C

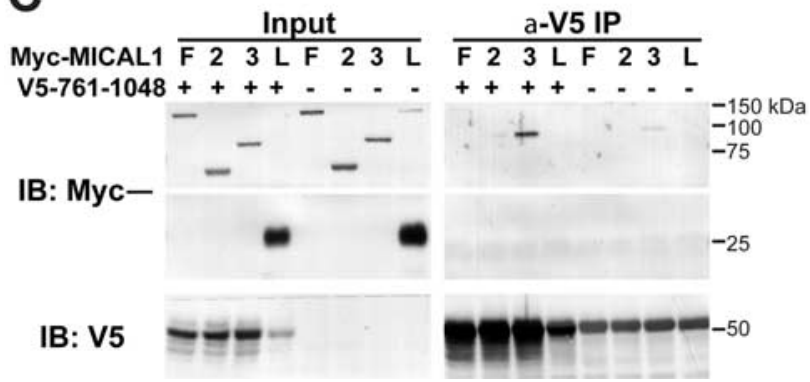

Figure 3. FAD-binding domain of MICAL 1 is constitutively active in $\operatorname{COS7}$ cells and is autoinhibited by the C-terminal region. $A, \operatorname{COS7}$ cells were transfected with the indicated plasmids and visualized with anti-Myc immunoflourescence. $\boldsymbol{B}$, Quantification of contraction of cells in $\boldsymbol{A}$ (mean \pm SEM). Cells with an area $\leq 1600 \mathrm{~mm}^{2}$ were defined as contracted. Below the graph is schematic of the tMICAL proteins. Although cells expressing full-length MICAL remain spread, cells expressing MICAL with truncations downstream of the FAD-binding region are contracted. When the FAD-binding domain is deleted, the cells fail to contract. Coexpression of the C-terminal domain (761-1048) inhibited the constitutive activity of 1-760 but not 1-630. C, HEK293T cells were transfected with the indicated plasmids, and V5-tagged C-terminal domain of MICAL (761-1048) was immunoprecipitated from lysates using anti-V5 antibodies. A small amount of full-length MICAL1 coimmunoprecipitated; however, a large amount of MICAL 1-760 copurified. Neither MICAL 1-630 nor the LIM domain only (L) showed a strong interaction with the C-terminal domain.

ages that were slightly higher than background of tMICAL 450 $1048(23 \%)$. Although this difference did not reach statistical significance, there may be weak activity of the FL-MICAL. It should also be noted that fewer cells were observed expressing tMICAL 1-450 compared with all of the other proteins, which could potentially be a result of compromised health after replating or decreased attachment to tissue culture plates.

Overexpression of tMICAL mutants lacking the FAD-binding domain failed to cause cell contraction (Fig. $3 A, B$ ), suggesting that this region was responsible for the constitutive activity of tMICAL 1-450, 1-630, and 1-760. These data also suggest that the C-terminal region of MICAL may inhibit the activity of the FAD-binding domain in the full-length protein. To test this hypothesis, the C-terminal 290 amino acids of MICAL (tMICAL 761-1048) were coexpressed with tMICAL 1-630 and 1-760. Remarkably, coexpression of the C-terminal domain attenuated the constitutive activity of tMICAL 1-760; however, it failed to block the contraction of tMICAL 1-630 overexpressing cells (Fig. 3B). Therefore, reconstitution of the full-length protein was necessary for inhibition.

We next looked to see whether the C-terminal domain of MICAL can physically interact with the $\mathrm{N}$-terminal portion of the protein to mediate autoinhibitory effects. HEK293T cells were cotransfected with expression vectors for V5-tagged tMICAL 761-1048 and either Myc-tagged full-length MICAL1, tMICAL 1-630, or tMICAL 1-760, and lysates were subjected to anti-V5 immunoprecipitation. MyctMICAL 1-760 coprecipitated with V5-Cterminal domain (Fig. $3 C$ ). There was no anti-Myc immunoreactive band in immunoprecipitates of tMICAL 1-630 cotransfected cells and only a weak band with fulllength MICAL. Together, these data suggest that the C-terminal domain of MICAL may interact with the rest of the protein between amino acids 631-760. This region includes the LIM domain; however, Myc-tagged LIM domain by itself was unable to interact with the $\mathrm{C}$-terminal domain (Fig. $3 C$ ). It is likely that MICALMICAL binding is mediated by cisinteractions, because the full-length protein showed a weaker coimmunoprecipitation with V5-tMICAL 761-1048 than the truncation deletion mutant lacking the C-terminal domain (tMICAL 1-760) (Fig. 3C). Similar to MICAL-CRMP interactions, interactions of C-terminal MICAL with the rest of the protein may be mediated by multiple residues near the LIM domain organized throughout the globular protein.

\section{C-terminal domain of MICAL inhibits enzymatic activity}

With traditional flavin monooxygenases, either nicotinamide adenine dinucleotide phosphate or NADPH is used for the reduction of FAD and subsequently the transfer of an oxygen atom to the substrate (Massey, 1994, 1995). The reduced form of the flavoenzyme reacts with molecular oxygen to form a detectable flavin $\mathrm{C}(4 \mathrm{a})$ hydroperoxide intermediate, which in the absence of substrate, decomposes to produce hydrogen peroxide and reoxidized FAD (Massey, 1994, 1995). Indeed, it has been shown that MICAL is an NADPH-dependent enzyme (Nadella et al., 2005; Siebold et al., 2005). A previous report demonstrated the use of an enzyme-linked assay to measure the activity of purified MICAL FAD-binding monooxygenase domain 
(amino acids 1-489) based on hydrogen peroxide production (Nadella et al., 2005). We adapted this assay to test the activity of MICAL truncation mutants in lysates of transfected HEK293T cells. Hydrogen peroxide production was detected in solution using the Amplex Red Reagent, which reacts in a 1:1 stoichiometry with hydrogen peroxide in the presence of horseradish peroxidase to produce a dye that can be detected by absorption at $560 \mathrm{~nm}$. Figure $4 \mathrm{~A}$ depicts the mechanism and design of the assay.

No activity was detected in lysates from untransfected cells or cells transfected with full-length MICAL or tMICAL 451-1048, which lacks the FAD-binding enzymatic domain (Fig. 4B). Both tMICAL 1-630 and 1-760 showed measurable enzymatic activity using this assay (Fig. $4 B$ ). These data support the hypothesis that MICAL 1-630 and 1-760 are constitutively active, and full-length MICAL is autoinhibited by the C-terminal domain. In addition, these data suggest that the effects of the overexpression of C-terminal MICAL truncation mutants on COS-7 cell morphology are likely a result of constitutive enzymatic activity. Purified recombinant His-tagged tMICAL 1-760 was used to determine that the concentration of active MICAL in the lysates corresponded to $\sim 1 \mu \mathrm{M}$ of protein (data not shown).

We directly tested whether the C-terminal region of MICAL1 could inhibit the enzymatic activity of TMICAL 1-630 and 1-760. Purified recombinant GST-tMICAL 761-1048 was added to lysates of HEK293T cells transfected with either Myc-tMICAL 1-630 or 1-760. A 20$25 \%$ decrease in hydrogen peroxide production was detected when $0.1 \mu \mathrm{M}$ GST-tMICAL 761-1048 was added compared with untreated lysates in both cases (Fig. 4C). Also, the addition of $1 \mu \mathrm{M}$ of the C-terminal domain led to a $\sim 75 \%$ decrease in enzyme activity. The addition of purified GST did not alter the activity of the constitutively active MICAL proteins (Fig. 4C), demonstrating the specificity of the GST-tMICAL 761-1048 effect. In the presence of $1 \mu \mathrm{M}$ GST-tMICAL 761-1048, the ability of NADPH to activate hydrogen peroxide production is severely impaired for both tMICAL 1-630 and 1-760 (Fig. 4C, insets), suggesting that GST-tMICAL 761-1048 modulates MICAL activity by altering NADPH kinetics. The presence of GST fusion proteins had no effect on the efficiency of the assay to detect hydrogen peroxide (data not shown).

\section{Coexpression of CRMP and MICAL leads to cell contraction}

To test the functional significance of the interactions between MICAL and CRMP, COS-7 cells were transfected with expression vectors for both proteins. Cells coexpressing Myc-MICAL1 and V5-CRMP1 showed a significant increase in contraction compared with cells expressing each protein individually (Fig. $5 A, B$ ). These data suggest that the coexpression of these proteins is suf-

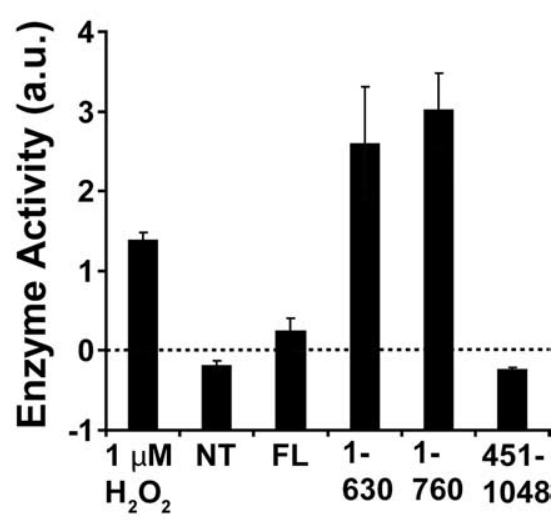

tMICAL 1-630

tMICAL 1-760

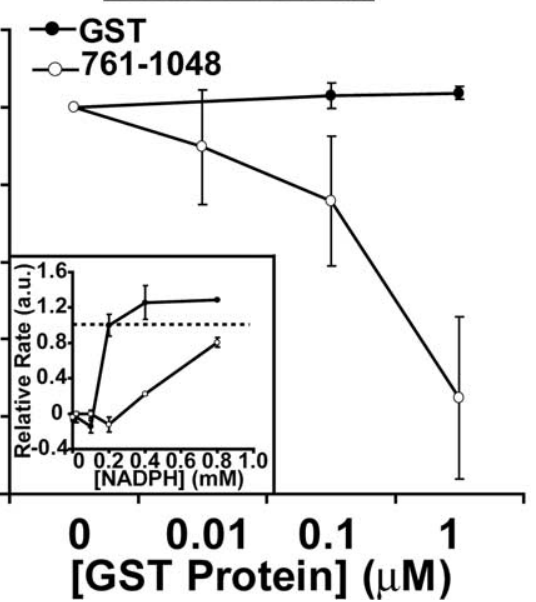

Figure 4. Measurement of MICAL enzymatic activity. $\boldsymbol{A}$, A flow chart depicting the assay design. Addition of NADPH leads to the reduction of $F A D$; however, the intermediate hydroperoxide form of the enzyme is unstable in the absence of substrate and matic activity, whereas NT, FL, and 451-1048 lacked activity. C, Quantification of the activity of tMICAL 1-630 and 1-760 with increasing concentrations of GST-761-1048 (mean + SEM). The addition of (-terminal domain decreased consitutive activity and shifted the concentration dependence for NADPH (inset).

ficient to activate a signaling pathway leading to changes in cell morphology. Two possible mechanisms by which this could occur are that CRMP positively modulates MICAL enzymatic activity or CRMP is modified by MICAL enzymatic activity and this in turns leads to cell contraction.

To distinguish these possibilities, NADPH-dependent hydrogen peroxide production by MICAL-expressing cell lysates was measured from cells cotransfected with CRMP1 using the Amplex Red Assay (Fig. 5C). CRMP1 coexpression did not significantly alter FL-MICAL enzymatic activity but suppressed the activity dependent on truncated tMICAL 1-730. These data do not fit with the hypothesis that CRMP activates MICAL. To explore further the possibility that MICAL modifies CRMP, purified recombinant GST WT CRMP1 (amino acids 8-525) was added to the lysates of cells transfected with either full-length MICAL or the constitutively active tMICAL 1-760. The presence of CRMP was not able to cause a detectable increase in hydrogen peroxide production from full-length MICAL lysates (Fig. 5D, left). A dramatic reduction in hydrogen peroxide production was seen when CRMP1 was added to tMICAL 1-760 lysates at concentrations of 
A
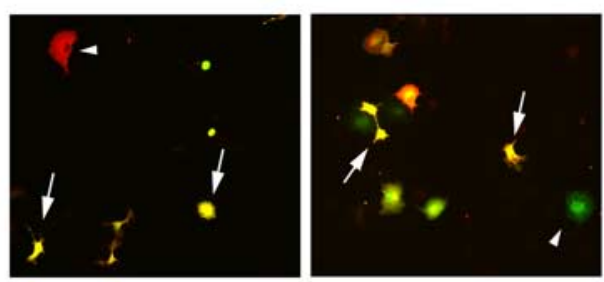

B

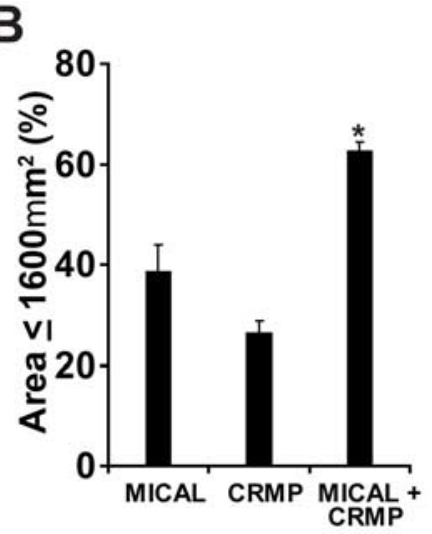

D
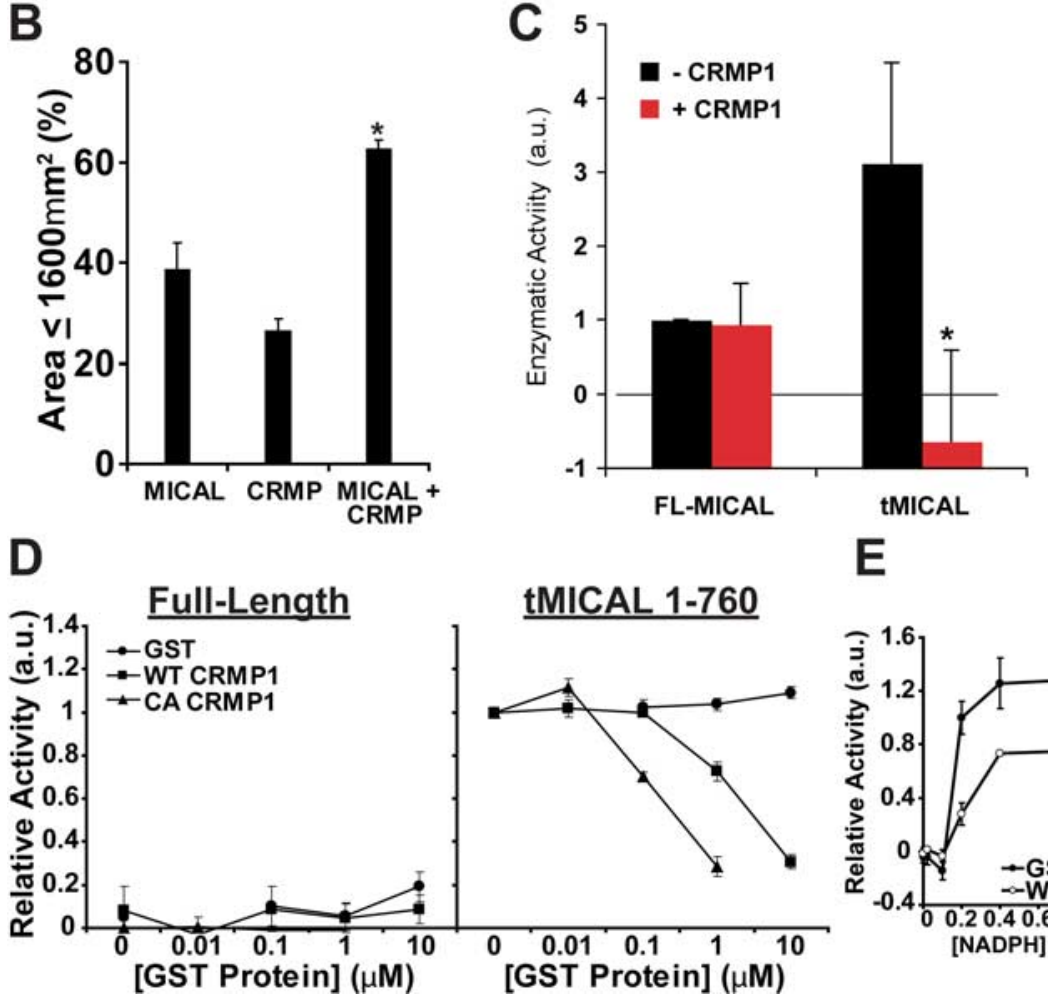

E

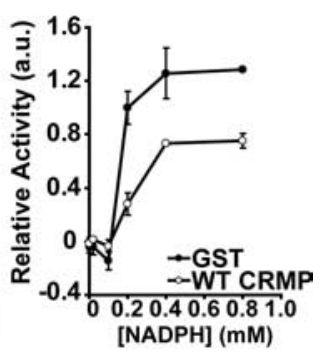

Figure 5. Coexpression of CRMP and MICAL alters cell shape, and CRMP alters MICAL enzymatic activity. $A$, COS7 cells transfected with Myc-MICAL1 and V5-CRMP1 were visualized with anti-Myc (red) or anti-V5 (green) immunofluorescence. Cells expressing either MICAL1 alone or CRMP1 alone appeared spread (arrowheads), whereas many of the cells expressing both proteins were contracted (arrows). $\boldsymbol{B}$, Quantification of contraction (cell area, $\leq 1600 \mathrm{~mm}^{2}$ ) of cells from $\boldsymbol{A}$ (mean + SEM; data are from 3 experiments; ${ }^{*} p<0.05$ ). Sixty-one percent of the cells expressing both proteins were contracted. $C_{1} \mathrm{H}_{2} \mathrm{O}_{2}$ production from lysates of HEK293T cells cotransfected with indicated FL-MICAL, TMICAL 1-760, and CRMP1 expression vectors in the presence of $200 \mu \mathrm{M}$ NADPH (mean + SEM; data are from 3 experiments; ${ }^{*} p<0.05$ comparing with and without CRMP1). D, Quantification of the rate of $\mathrm{H}_{2} \mathrm{O}_{2}$ production by MICAL enzymatic activity in HEK293T lysates after the addition of purified GST-tagged WT or CA CRMP1. Both WT and CA CRMP1 decreased enzyme activity with CA CRMP1 being as effective at a concentration an order of magnitude lower than WT CRMP1. E, MICAL activity was measured in the presence of $1 \mu \mathrm{m}$ GST or $1 \mu \mathrm{M}$ GST-WT CRMP1 at various NADPH concentrations. The effect of WT CRMP1 on MICAL1 activity was not caused by alterations in NADPH affinity.

1 and $10 \mu \mathrm{M}$ (Fig. 5D, right). The addition of the CA CRMP1 (mCRMP1 [49-56]) (Deo et al., 2004) was also effective at reducing hydrogen peroxide production from tMICAL $1-760$ at a much lower concentration than WT CRMP1.

Initially, these data seemed contradictory to observations of cell morphology, because, in this assay, CRMP appeared to inactivate MICAL enzyme activity. However, the assay used measures hydrogen peroxide production by MICAL, which is believed to occur only in the absence of substrate (Massey, 1994; Nadella et al., 2005; Siebold et al., 2005). It is predicted that in the presence of substrate, the MICAL ${ }^{*}-\mathrm{FADH}-\mathrm{OOH}$ intermediate is blocked from bulk solvent and therefore does not degrade to hydrogen peroxide. Therefore, the lack of hydrogen peroxide production would make it appear that the enzyme is inactive in this assay.
Unlike the MICAL C-terminal region, the attenuation of hydrogen peroxide production by WT CRMP1 does not alter NADPH concentration dependency (Fig. 5E), consistent with the possibility that CRMP1 exerts its action as a substrate inhibitor not a cofactor inhibitor of the enzyme. One intriguing possibility is that an amino acid side chain of CRMP1 serves as a substrate for MICAL monooxygenase activity (see Discussion).

Truncation of the FAD-binding domain of MICAL1 results in a dominant-negative protein

The effect of expression of MICAL mutants lacking the FAD-binding region on semaphorin-mediated COS-7 contraction was tested. Sema3A-mediated contraction was examined in COS-7 cells expressing PlexA1/NRP1 Sema3A receptors alone or with full-length MICAL, tMICAL 4511048, or tMICAL 761-1048. Note that Sema3F is used here as a histological reagent that detects the expression of NRP-1 but does not activate this Sema3A receptor (Takahashi et al., 1998, 1999). The coexpression of full-length MICAL1 with PlexA1/NRP1 led to the majority of cells showing a contracted morphology in all treatment groups (Fig. 6). This effect was independent of neuropilin and Semaphorin treatment, because cells overexpressing only PlexA1 and full-length MICAL1 were constitutively contracted (Fig. 6B, black bar). Similar to previous published observations (Takahashi et al., 1999; Deo et al., 2004), Sema3A treatment led to a significant increase in contraction of PlexA1/NRP1-expressing cells compared with control Sema3F treatment (Fig. $6 A, B)$. Coexpression of tMICAL 451-1048 or 761-1048 significantly attenuated the Sema3A-mediated contraction (Fig. 6B). These data suggest that truncation of the FAD-binding domain leads to a dominantnegative protein in a heterologous assay measuring Sema3A responses.

Next, HSV vectors were used to overexpress MICAL truncation mutants in dissociated chick DRG neurons to assess the effect of these proteins on neurite outgrowth. None of the proteins exhibited adverse effects on the overall health or survival of the cells (data not shown). Neurons overexpressing full-length MICAL, tMICAL 451-1048, or tMICAL 7611048 did not show any significant changes in neurite length when compared with untreated control cells overexpressing green fluorescent protein (GFP) (Fig. $7 A, B$ ) (data not shown). However, overexpression of tMICAL $1-760$ led to a $\sim 27 \%$ decrease in outgrowth relative to GFP controls (Fig. $7 B$ ). This effect was very similar to the $\sim 28 \%$ decrease in outgrowth observed in GFP overexpressing cells that were grown for $5 \mathrm{~h}$ in the presence of Sema3A, demonstrating that TMICAL 1-760 exhibits constitutive activity when expressed in neurons. Additionally, these observa- 
A

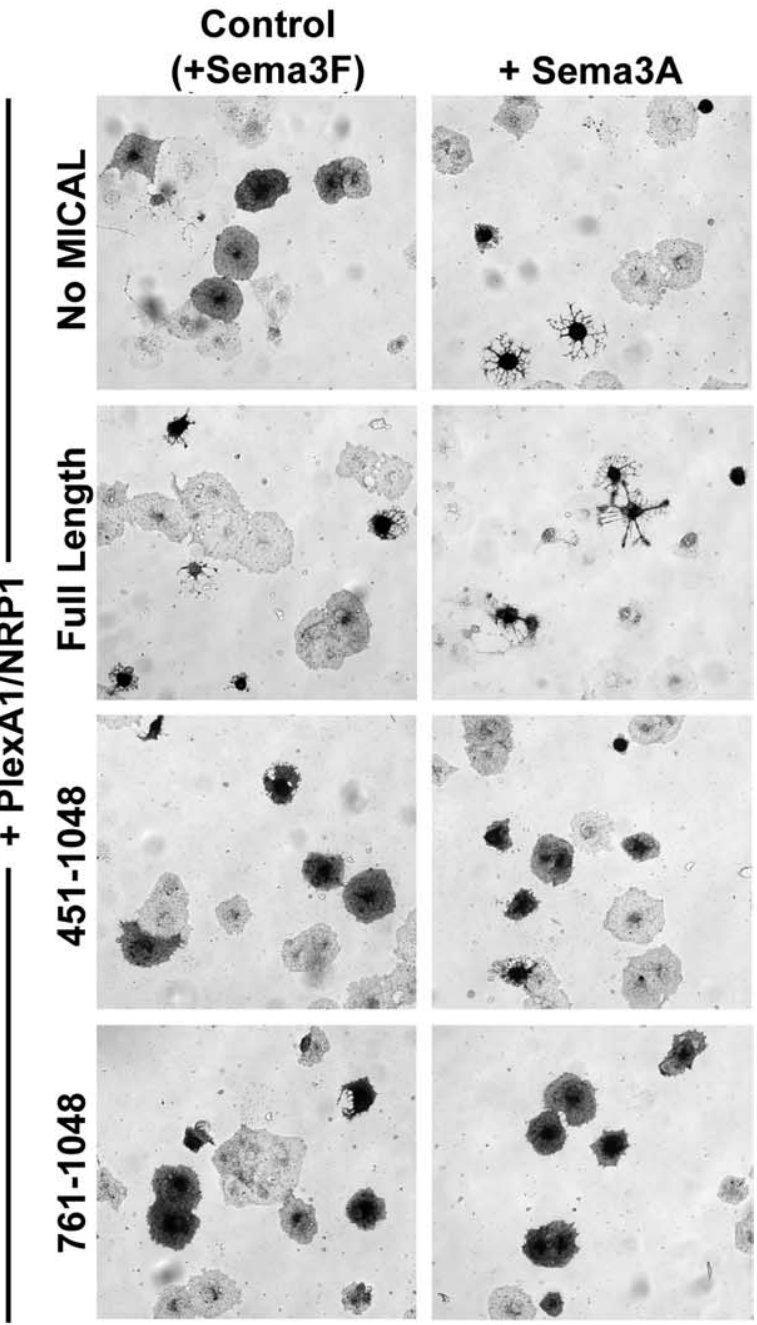

B

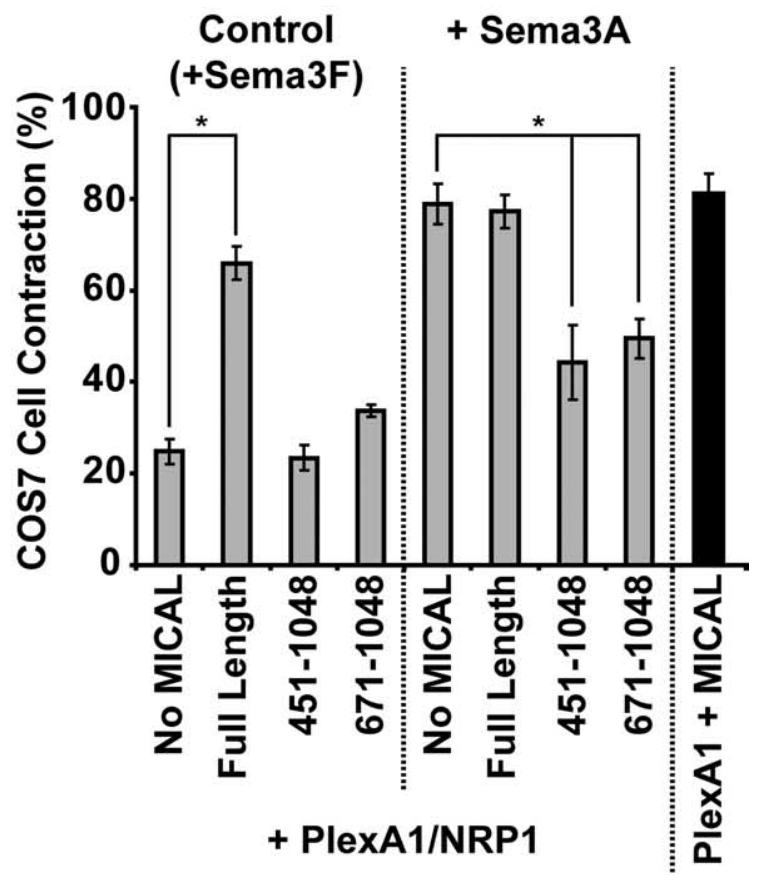

Figure 6. C-terminal domain of MICAL1 is dominant negative in Sema3A-mediated COS7 contraction. A, COS7 cells were transfected with PlexA1/NRP1 together with vector, full-length MICAL1, tMICAL 451-1048, or tMICAL 761-1048 were incubated with AP-Sema3A or AP- tions match precisely the effect of the overexpression of the CA CRMP mutant described previously (Deo et al., 2004).

Because tMICAL mutants lacking the enzyme domain were able to attenuate Sema3A-mediated COS7 contraction, it was important to determine whether such dominant-negative activity could occur in neuronal responses to Sema3A. As stated above, GFP overexpressing neurons show a $\sim 28 \%$ decrease in outgrowth when grown in the presence of Sema3A. This effect was abolished in neurons overexpressing tMICAL 451-1048 or tMICAL 761-1048 (Fig. 7C), suggesting that these mutant proteins, indeed, exhibit a dominant-negative behavior in neurons and that the C-terminal domain is sufficient for these effects. Interestingly, tMICAL 1-760 did not significantly attenuate Sema3A responses (data not shown). This is again consistent with the observations for CA CRMP (Deo et al., 2004).

To assess the specificity of the tMICAL for Sema3A signaling, responses to clustered ephrinA5 were examined in parallel. The maximal percentage of E7 DRG growth cones collapsed by Sema3A is greater than for ephrin-A5 (Fig. 7D), as expected (Nakamura et al., 1998; Takahashi et al., 1998; Munoz et al., 2005). In tMICAL expression studies, a $5 \mathrm{~nm}$ concentration of ephrinA5 or Sema3A was used (Fig. 7A-C), because this is less than twofold above the $\mathrm{EC}_{50}$ value of each molecule for growth cone collapse (Fig. 7D) and allows assays with the two ligands to be sensitive in detecting a tMICAL blocking effect, if present. Overexpression of tMICAL proteins did not have any effect on neuronal responses to clustered ephrinA5 (Fig. $7 A, C$ ), demonstrating that the effect of mutants on neurite outgrowth was specific to Sema3A signaling pathway.

\section{Discussion}

The present study identifies a protein complex consisting of Plexins, MICAL1, and CRMPs mediating Sema3A signaling. Truncation mutagenesis of MICAL1 revealed that mutant proteins lacking the C-terminal 290 amino acids were constitutively active in both a cell morphology assay as well as an in vitro system using an enzyme-linked assay to indirectly measure the monooxygenase activity of MICAL. In addition, the C-terminal domain of MICAL acted to autoinhibit the N-terminal FAD-binding enzyme domain. CRMP altered MICAL activity in vitro, and the mechanistic consequence of this observation is likely to be a fruitful ground for additional biochemical studies. Finally, we provide evidence to suggest MICAL truncation mutants lacking the FADbinding domain act as dominant-negative proteins in both the heterologous Sema3A-mediated COS7 contraction assay and attenuate neuronal responses to Sema3A. Together, these data begin to elucidate a mechanism for the activation and regulation of MICAL enzymatic activity and the initiation of semaphorin signaling inside the cell.

The involvement of MICAL in semaphorin signaling was first described in flies (Terman et al., 2002). These studies demonstrated that proper SemalA axon guidance was dependent on the

Sema3F conditioned media for $1 \mathrm{~h}$ at $37^{\circ} \mathrm{C}$ and visualized by staining for bound AP. Sema3A activates NRP1 receptors, whereas Sema3F binds to these receptor without activating them (Takahashi et al., 1998, 1999). B, Quantification of contraction of cells from $\boldsymbol{A}$. The cell area was measured, and the percentage of contracted cells (area $\leq 1600 \mu \mathrm{m}^{2}$ ) is shown (mean \pm SEM). Cells expressing PlexA1/NP1 and MICAL 451-1048 or MICAL 761-1048 showed reduced contraction in response to AP-Sema $3 \mathrm{~A}$ challenge ( $\sim 44-48 \%$ contracted) compared with cells expressing only PlexA1/NRP1 ( $\sim 78 \%$ contracted). The coexpression of PlexA1 and full-length MICAL led to cell contraction in the absence of NRP1 or Sema3A treatment (black bar). ${ }^{*} p<$ 0.01 versus No MICAL value, Student's $t$ test. 
A
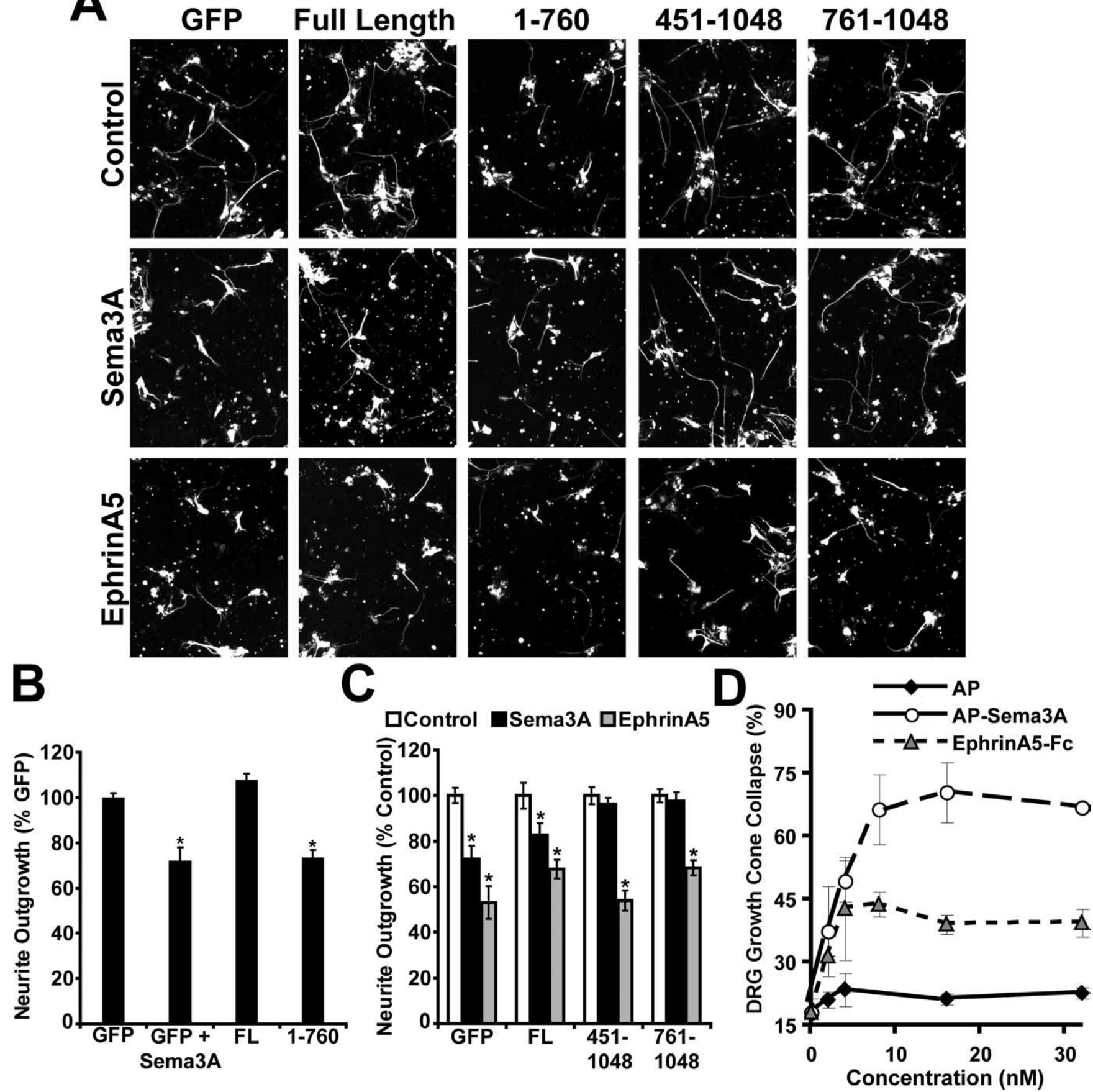

Figure 7. The effect of tMICALs on DRG neurite outgrowth. A, Dissociated E7 chick DRGs were treated with HSV vectors to overexpress GFP, full-length MICAL, or tMICAL mutants and grown in the presence of control, $5 \mathrm{~nm}$ AP-Sema $3 \mathrm{~A}$, or $5 \mathrm{~nm}$ clustered ephrinA5 conditioned media. Infected neurons were visualized by double immunofluorescent staining with anti-Myc or anti-GFP (data not shown) together with anti-neurofilament to visualize axons (shown). B, Comparison of neurite outgrowth between control (GFP) cells and cells overexpressing FL-MICAL1, tMICAL 1-760, or Sema3A-treated control cells (GFP + Sema3A) from $\boldsymbol{A}$. Mean neurite outgrowth was measured and is presented as a percentage of the mean outgrowth from GFP-overexpressing cells (mean + SEM). Both Sema3A treatment and overexpression of tMICAL 1-760 led to a significant decrease in neurite outgrowth when compared with control ( ${ }^{*} p \leq 0.01$, Student's $t$ test). C, Quanitification of the effect of Sema3A and ephrinA5 treatment on the neurite outgrowth of the cells overexpressing GFP, FL-MICAL, tMICAL 451-1048 (451-1048), or tMICAL 761-1048 (461-1048) from A. Data are expressed as percentage of mean outgrowth of control conditioned media (mean \pm SEM). Although GFP and FL-MICAL overexpressing cells showed a decrease in outgrowth in the presence of Sema3A, this effect was not seen in cells overexpressing tMICAL 451-1048 or 761-1048. All groups showed attenuated outgrowth when treated with clustered ephrinA5 $\left({ }^{*} p \leq 0.01 ;\right.$ Student's $t$ test). D, Dose-response curve for E7 chick DRG growth cone collapse by AP-Sema3A and by clustered ephrinA5-Fc. The concentration of ephrinA5-Fc is expressed for total ephrinA5 molecules and is not corrected for the degree of clustering. A dose of $5 \mathrm{~nm}$ was used for the experiments in $\boldsymbol{A}-\boldsymbol{C}$.

monooxygenase activity of MICAL. In addition, the green tea extract EGCG, which is known to inhibit other flavin monooxygenases (Abe et al., 2000a,b), was shown to specifically block growth cone responses to Sema3A in vitro, further supporting a role for redox activity in axon guidance (Terman et al., 2002; Pasterkamp et al., 2005). Our results from COS-7 cells overexpressing truncation mutants add to these observations by demonstrating that the enzymatic activity is autoinhibited by the 
C-terminal domain in the full-length protein, and release of this inhibition induces morphological changes similar to the addition of Sema3A in PlexA1/NRP1 overexpressing cells. Additionally, expression of truncation mutants lacking the FAD-binding domain was able to attenuate Sema3A-induced changes in cell morphology and neurite outgrowth in neurons.

The observation that C-terminal domain of MICAL can bind to the rest of the protein and modulate the enzyme activity is a novel finding with broad implications for understanding the mechanism of signaling. The $\mathrm{COOH}$-terminal region contains the residues that mediate interactions with Plexin in flies and vertebrates (Terman et al., 2002). An attractive hypothesis is that Plexin binding to the $\mathrm{C}$ terminus disrupts the interaction of MICAL C terminus with the enzymatic domain, releasing autoinhibition and leading to the activation of the monooxygenase activity. Interestingly, other MICAL-interacting proteins, including the small GTPase, Rab1, CasL, and vimentin, have all been shown to bind to residues within the last 290 amino acids MICAL (Suzuki et al., 2002; Weide et al., 2003). Therefore, a number of signaling pathways may converge at this site to modulate MICAL activity. CRMP does not appear to bind to residues in the $\mathrm{C}$ terminus but rather to $\mathrm{N}$ terminal domain, including the FAD binding and LIM domains. This region overlaps with the sitemediating interactions between $\mathrm{N}$-terminal and C-terminal MICAL. Therefore, it is possible that Plexin binding results in conformational changes that allow CRMP to bind. Alternatively, CRMP binding may function to displace the $\mathrm{N}$ - and C-terminal interactions independently, or in concert with Plexin.

Analyses of the crystal structure of the FAD-binding monooxygenase domain of mouse MICAL1 revealed that the enzyme is most stable in the "out" conformation in which the bound FAD is oxidized (Nadella et al., 2005; Siebold et al., 2005). Addition of NADPH leads to the reduction of FAD and a structural change to the "in" conformation. Unlike other hydroxylases, such as $\mathrm{PHBH}$, the reduced isoalloxizine ring of FAD is exposed to bulk solvent in the "in" conformation, which results in a decay to hydrogen peroxide and oxidized FAD in the absence of substrate (Fraaije and Mattevi, 2000; Nadella et al., 2005; Siebold et al., 2005). Therefore, a tight coordination of NADPH binding and accessibility of substrate is required for effective enzymatic function (Siebold et al., 2005). Our preliminary observations suggest that the C-terminal domain of MICAL attenuates enzymatic activity by reducing NADPH affinity. We determined that MICAL C-terminal region binds near the MICAL LIM domain and not the enzyme domain. However, it is possible that a C-terminalLIM region interaction leads to a general conformational change that indirectly alters NADPH affinity.

We also present data that raise the possibility that CRMP residues are a substrate for MICAL hydroxylase activity. Structural data predict that MICAL differs from other hydroxylases in that a substrate(s) is likely macromolecular, such as a protein, rather than a small molecule (Entsch and van Berkel, 1995; Siebold et al., 2005). After reduction of the FAD and a change to the "in" conformation of the enzyme, a channel opens up on the surface of MICAL allowing for the active site to be accessible to residues on protein side chains (Siebold et al., 2005). The method we used to measure MICAL activity is an indirect enzyme-linked assay that measures hydrogen peroxide production. Addition of CRMP reduced the production of hydrogen peroxide of constitutively active MICAL; however, this reduction was not a result of NADPH kinetics. Therefore, CRMP may bind to the active site of MICAL, thus protecting the reduced FAD from molecular oxygen in solution and preventing the decay to hydrogen peroxide. Surpris- ingly, constitutively active CRMP1, mCRMP1(49-56), had a lower effective concentration than wild-type CRMP1. Although the mechanism of CRMP constitutive activity has not been determined, it is thought that residues mutated within the N-terminal "upper lobe" leads to an active conformation (Deo et al., 2004). An intriguing possibility is that residues within this region physically interact with the MICAL enzymatic domain, and CRMP may be a MICAL substrate.

Alternatively, CRMP may recruit a substrate to MICAL. Our previous studies revealed that CRMP tetramers share a high sequence homology with the dihydropyrimidinase family of enzymes, and the crystal structure of CRMP tetramers has a high structural homology to D-hydantoinase, both members of the metal-dependent amidohydrolases (Wang and Strittmatter, 1997; Deo et al., 2004). However, CRMP proteins lack detectable enzymatic activity because of the fact that residues critical for metal-binding and catalytic activity are missing in CRMP (Deo et al., 2004). It cannot be ruled out that CRMPs retain the ability to bind pseudo-substrate molecules and then present them to the enzymatic domain of MICAL.

Because CRMP and the MICAL C-terminal domain bind to an overlapping region near the LIM domain, an attractive model for the mechanism of MICAL-CRMP-Plexin complexes mediating signaling can be formed. Plexin binding to the $\mathrm{C}$ terminus of MICAL has a dual effect such that the CRMP-binding region is exposed and NADPH can bind, thus activating the hydroxylase activity. Such a model accounts for the coordination of enzyme activation and substrate presentation. The multiple protein interaction domains of MICAL suggest that it plays a role in mediating a large signaling complex (Suzuki et al., 2002; Terman et al., 2002; Weide et al., 2003; Fischer et al., 2005). Thus, it is likely a similar mechanism may exist for multiple signaling pathways, such as $\beta 1$-integrin signaling through CasL or the modulation of vesicle trafficking between Golgi and endoplasmic reticulum via Rab1.

Additional studies will be needed to elucidate the functional role of MICAL monooxygenase activity in Sema3 signaling. The simple generation of reactive oxygen species should not be ruled out as a possible mechanism of action (Ventura and Pelicci, 2002; Nadella et al., 2005). This may occur in addition to the modification of protein substrates depending on the context of signaling. Oxidation of proteins is generally thought to have toxic effects; however, there is precedence for it in cellular signaling (Finkel, 1998). For example, the activities of the small monomeric GTPases, Ras and Rac1, have been shown to be regulated by redox signaling (Lander et al., 1997), and oxidation of actin itself can regulate the dynamics of actin filaments (Pollard and Borisy, 2003). In any case, our results demonstrating the autoregulation of enzymatic activity and the identification of CRMP proteins as potential substrates help us to elucidate novel mechanisms for Sema3A signaling. These results identify new directions for future research.

\section{References}

Abe I, Kashiwagi K, Noguchi H (2000a) Antioxidative galloyl esters as enzyme inhibitors of p-hydroxybenzoate hydroxylase. FEBS Lett 483:131-134.

Abe I, Seki T, Umehara K, Miyase T, Noguchi H, Sakakibara J, Ono T (2000b) Green tea polyphenols: novel and potent inhibitors of squalene epoxidase. Biochem Biophys Res Commun 268:767-771.

Aizawa H, Wakatsuki S, Ishii A, Moriyama K, Sasaki Y, Ohashi K, SekineAizawa Y, Sehara-Fujisawa A, Mizuno K, Goshima Y, Yahara I (2001) Phosphorylation of cofilin by LIM-kinase is necessary for semaphorin 3A-induced growth cone collapse. Nat Neurosci 4:367-373.

Castellani V, Falk J, Rougon G (2004) Semaphorin3A-induced receptor en- 
docytosis during axon guidance responses is mediated by L1 CAM. Mol Cell Neurosci 26:89-100.

Deo RC, Schmidt EF, Elhabazi A, Togashi H, Burley SK, Strittmatter SM (2004) Structural bases for CRMP function in plexin-dependent semaphorin3A signaling. EMBO J 23:9-22.

Eickholt BJ, Walsh FS, Doherty P (2002) An inactive pool of GSK-3 at the leading edge of growth cones is implicated in Semaphorin 3A signaling. J Cell Biol 157:211-217.

Entsch B, van Berkel WJ (1995) Structure and mechanism of parahydroxybenzoate hydroxylase. FASEB J 9:476-483.

Finkel T (1998) Oxygen radicals and signaling. Curr Opin Cell Biol 10:248-253.

Fischer J, Weide T, Barnekow A (2005) The MICAL proteins and rab1: a possible link to the cytoskeleton? Biochem Biophys Res Commun 328:415-423.

Fournier AE, Nakamura F, Kawamoto S, Goshima Y, Kalb RG, Strittmatter SM (2000) Semaphorin3A enhances endocytosis at sites of receptor-Factin colocalization during growth cone collapse. J Cell Biol 149:411-422.

Fraaije MW, Mattevi A (2000) Flavoenzymes: diverse catalysts with recurrent features. Trends Biochem Sci 25:126-132.

Gimona M, Djinovic-Carugo K, Kranewitter WJ, Winder SJ (2002) Functional plasticity of CH domains. FEBS Lett 513:98-106.

Goshima Y, Nakamura F, Strittmatter P, Strittmatter SM (1995) Collapsininduced growth cone collapse mediated by an intracellular protein related to UNC-33. Nature 376:509-514.

He Z, Tessier-Lavigne M (1997) Neuropilin is a receptor for the axonal chemorepellent Semaphorin III. Cell 90:739-751.

Jin Z, Strittmatter SM (1997) Rac1 mediates collapsin-1-induced growth cone collapse. J Neurosci 17:6256-6263.

Jurney WM, Gallo G, Letourneau PC, McLoon SC (2002) Rac1-mediated endocytosis during ephrin-A2- and semaphorin $3 \mathrm{~A}$-induced growth cone collapse. J Neurosci 22:6019-6028.

Kolodkin AL, Levengood DV, Rowe EG, Tai YT, Giger RJ, Ginty DD (1997) Neuropilin is a semaphorin III receptor. Cell 90:753-762.

Lander HM, Hajjar DP, Hempstead BL, Mirza UA, Chait BT, Campbell S, Quilliam LA (1997) A molecular redox switch on p21(ras). Structural basis for the nitric oxide-p21(ras) interaction. J Biol Chem 272:4323-4326.

Luo Y, Raible D, Raper JA (1993) Collapsin: a protein in brain that induces the collapse and paralysis of neuronal growth cones. Cell 75:217-227.

Massey V (1994) Activation of molecular oxygen by flavins and flavoproteins. J Biol Chem 269:22459-22462.

Massey V (1995) Introduction: flavoprotein structure and mechanism. FASEB J 9:473-475.

Mitsui N, Inatome R, Takahashi S, Goshima Y, Yamamura H, Yanagi S (2002) Involvement of Fes/Fps tyrosine kinase in semaphorin3A signaling. EMBO J 21:3274-3285.

Munoz LM, Zayachkivsky A, Kunz RB, Hunt JM, Wang G, Scott SA (2005) Ephrin-A5 inhibits growth of embryonic sensory neurons. Dev Biol 283:397-408.

Nadella M, Bianchet MA, Gabelli SB, Barrila J, Amzel LM (2005) Structure and activity of the axon guidance protein MICAL. Proc Natl Acad Sci USA 102:16830-16835.

Nakamura F, Tanaka M, Takahashi T, Kalb RG, Strittmatter SM (1998) Neuropilin-1 extracellular domains mediate semaphorin D/III-induced growth cone collapse. Neuron 21:1093-1100.

Pasterkamp RJ, Kolodkin AL (2003) Semaphorin junction: making tracks toward neural connectivity. Curr Opin Neurobiol 13:79-89.
Pasterkamp RJ, Dai HN, Terman JR, Wahlin KJ, Kim B, Bregman BS, Popovich PG, Kolodkin AL (2005) MICAL flavoprotein monooxygenases: expression during neural development and following spinal cord injuries in the rat. Mol Cell Neurosci 31:52-69.

Pollard TD, Borisy GG (2003) Cellular motility driven by assembly and disassembly of actin filaments. Cell 112:453-465.

Sasaki Y, Cheng C, Uchida Y, Nakajima O, Ohshima T, Yagi T, Taniguchi M, Nakayama T, Kishida R, Kudo Y, Ohno S, Nakamura F, Goshima Y (2002) Fyn and Cdk5 mediate semaphorin-3A signaling, which is involved in regulation of dendrite orientation in cerebral cortex. Neuron 35:907-920.

Sattler M, Salgia R, Shrikhande G, Verma S, Uemura N, Law SF, Golemis EA, Griffin JD (1997) Differential signaling after betal integrin ligation is mediated through binding of CRKL to p120(CBL) and p110(HEF1). J Biol Chem 272:14320-14326.

Siebold C, Berrow N, Walter TS, Harlos K, Owens RJ, Stuart DI, Terman JR, Kolodkin AL, Pasterkamp RJ, Jones EY (2005) High-resolution structure of the catalytic region of MICAL (molecule interacting with CasL), a multidomain flavoenzyme-signaling molecule. Proc Natl Acad Sci USA 102:16836-16841.

Suzuki T, Nakamoto T, Ogawa S, Seo S, Matsumura T, Tachibana K, Morimoto C, Hirai H (2002) MICAL, a novel CasL interacting molecule, associates with vimentin. J Biol Chem 277:14933-14941.

Takahashi T, Strittmatter SM (2001) Plexinal autoinhibition by the plexin sema domain. Neuron 29:429-439.

Takahashi T, Nakamura F, Jin Z, Kalb RG, Strittmatter SM (1998) Semaphorins $\mathrm{A}$ and $\mathrm{E}$ act as antagonists of neuropilin-1 and agonists of neuropilin-2 receptors. Nat Neurosci 1:487-493.

Takahashi T, Fournier A, Nakamura F, Wang LH, Murakami Y, Kalb RG, Fujisawa H, Strittmatter SM (1999) Plexin-neuropilin-1 complexes form functional semaphorin-3A receptors. Cell 99:59-69.

Tamagnone L, Artigiani S, Chen H, He Z, Ming GI, Song H, Chedotal A, Winberg ML, Goodman CS, Poo M, Tessier-Lavigne M, Comoglio PM (1999) Plexins are a large family of receptors for transmembrane, secreted, and GPI-anchored semaphorins in vertebrates. Cell 99:71-80.

Terman JR, Mao T, Pasterkamp RJ, Yu HH, Kolodkin AL (2002) MICALs, a family of conserved flavoprotein oxidoreductases, function in plexinmediated axonal repulsion. Cell 109:887-900.

Togashi H, Schmidt EF, Strittmatter SM (2006) RanBPM contributes to Semaphorin3A signaling through plexin-A receptors. J Neurosci 26:4961-4969.

Toyofuku T, Yoshida J, Sugimoto T, Zhang H, Kumanogoh A, Hori M, Kikutani H (2005) FARP2 triggers signals for Sema3A-mediated axonal repulsion. Nat Neurosci 8:1712-1719.

Turner LJ, Hall A (2006) Plexin-induced collapse assay in COS cells. Methods Enzymol 406:665-676.

Turner LJ, Nicholls S, Hall A (2004) The activity of the plexin-A1 receptor is regulated by Rac. J Biol Chem 279:33199-33205.

Ventura A, Pelicci PG (2002) Semaphorins: green light for redox signaling? Sci STKE 2002:PE44.

Wang LH, Strittmatter SM (1997) Brain CRMP forms heterotetramers similar to liver dihydropyrimidinase. J Neurochem 69:2261-2269.

Weide T, Teuber J, Bayer M, Barnekow A (2003) MICAL-1 isoforms, novel rabl interacting proteins. Biochem Biophys Res Commun 306:79-86.

Zanata SM, Hovatta I, Rohm B, Puschel AW (2002) Antagonistic effects of Rnd1 and RhoD GTPases regulate receptor activity in Semaphorin 3Ainduced cytoskeletal collapse. J Neurosci 22:471-477. 